University of Nebraska - Lincoln

DigitalCommons@University of Nebraska - Lincoln

Faculty Publications: Department of

Entomology

Entomology, Department of

April 2006

\title{
Assessing Risk of Resistance to Aerial Applications of Methyl- \\ Parathion in Western Corn Rootworm (Coleoptera: Chrysomelidae)
}

\author{
Michael A. Caprio \\ Mississippi State University, Mississippi State, MS \\ Tim Nowatski \\ University of Nebraska-Lincoln \\ Blair Siegfried \\ University of Nebraska-Lincoln, bsiegfried1@ufl.edu \\ Lance J. Meinke \\ University of Nebraska-Lincoln, Imeinke1@unl.edu \\ Robert J. Wright \\ University of Nebraska-Lincoln, rwright2@unl.edu \\ See next page for additional authors
}

Follow this and additional works at: https://digitalcommons.unl.edu/entomologyfacpub

Part of the Entomology Commons

Caprio, Michael A.; Nowatski, Tim; Siegfried, Blair; Meinke, Lance J.; Wright, Robert J.; and Chandler, Larry D., "Assessing Risk of Resistance to Aerial Applications of Methyl-Parathion in Western Corn Rootworm (Coleoptera: Chrysomelidae)" (2006). Faculty Publications: Department of Entomology. 49.

https://digitalcommons.unl.edu/entomologyfacpub/49

This Article is brought to you for free and open access by the Entomology, Department of at DigitalCommons@University of Nebraska - Lincoln. It has been accepted for inclusion in Faculty Publications: Department of Entomology by an authorized administrator of DigitalCommons@University of Nebraska - Lincoln. 
Authors

Michael A. Caprio, Tim Nowatski, Blair Siegfried, Lance J. Meinke, Robert J. Wright, and Larry D. Chandler 


\title{
Assessing Risk of Resistance to Aerial Applications of Methyl-Parathion in Western Corn Rootworm (Coleoptera: Chrysomelidae)
}

\author{
MICHAEL A. CAPRIO, ${ }^{1}$ TIM NOWATZKI,${ }^{2}$ BLAIR SIEGFRIED, ${ }^{2}$ LANCE J. MEINKE, ${ }^{2}$ \\ ROBERT J. WRIGHT, ${ }^{2}$ AND LARRY D. CHANDLER ${ }^{3}$
}

\begin{abstract}
J. Econ. Entomol. 99(2): 483-493 (2006)
ABSTRACT We validated a stochastic model of the evolution of resistance to adulticidal sprays of methyl-parathion in western corn rootworm, Diabrotica virgifera virgifera LeConte, populations in Nebraska. The population dynamics predicted by the model resembled that reported for field populations, and time until control failures occurred closely matched reports by commercial crop consultants. We incorporated uncertainty about the values used for 18 model parameters by replacing default values with random draws taken from a normal distribution. One parameter, the initial resistance allele frequency, was no longer measurable because of the evolution of resistance. We therefore proposed five candidate initial allele frequencies and developed probability distributions for the time to resistance for each by running 1000 simulations with parameters randomly varied. These distributions included variation because of stochastic effects as well as parameter uncertainty. We used Bayesian inference to estimate the candidate frequency most likely, given reported times to field control failures. The initial allele frequency of $10^{-4}$ was most likely $(29 \%), 10^{-3}$ was less likely $(28 \%)$, whereas $10^{-6}$ was relatively unlikely $(5 \%)$. Results from sensitivity analysis depended upon how evolution of resistance was measured. When resistance was examined as a genetic phenomenon, the rate of increase of the resistance allele depended almost entirely on genetic factors ( $\mathrm{LC}_{50}$ values), the characteristics of the pesticide (residual activity), and the variance associated with emergence of adults. When resistance was measured as failure of methyl-parathion to reduce populations below threshold levels ( 0.5 gravid females per plant), parameters that contributed to population growth rate (mortality and fecundity) were also important. These data suggest two important phases in resistance evolution in corn rootworms: a genetic phase associated with negative growth rates and rapid changes in resistance allele frequencies and a rebound phase associated with positive growth rates and near fixation of the resistance allele.
\end{abstract}

KEY WORDS Insecticide resistance, corn rootworm, sensitivity analysis, parameter uncertainty, Diabrotica virgifera virgifera

Western corn rootworm, Diabrotica virgifera virgifera LeConte, is a perennial insect pest of corn, Zea mays L., across the Corn Belt. Economic loss from this pest is most severe when corn is grown in the same field for successive years (continuous corn). Western corn rootworm is univoltine and overwinters as eggs, typically in the soil of a cornfield. Egg hatch begins in late May or early June, and the larvae complete three stages feeding on the roots of corn. Larval feeding on the roots can significantly reduce grain yield by limiting water and nutrient uptake and by weakening the plant, increasing its susceptibility to lodging (Levine and Oloumi-Sadeghi 1991). Adult emergence typically begins in late June or early July, and beetles can be present in the cornfield until the first killing frost in fall.

\footnotetext{
${ }^{1}$ Mississippi State University, Mississippi State, MS 39762

${ }^{2}$ University of Nebraska-Lincoln, Lincoln, NE 68583.

${ }^{3}$ USDA-ARS, Fargo, ND 58105.
}

The primary management tactics used against corn rootworms have been crop rotation with a nonhost crop, prophylactic treatment with soil insecticides applied at planting, or application of foliar insecticides targeted to the adults to reduce oviposition and prevent significant root injury in the field the following season (Levine and Oloumi-Sadeghi 1991). However, in certain regions of the Corn Belt, the sustainability of these control tactics has been challenged by the western corn rootworm's ability to adapt to and overcome management strategies that impose intense selection pressure.

Crop rotation has traditionally been a very effective management tool for western corn rootworms. Since the early 1990s, however, damage to first-year corn following soybean in east central Illinois and northwestern Indiana has become severe (Levine and Oloumi-Sadeghi 1996). Recent studies have led researchers to suspect that long-term use of corn-soybean crop rotation in this region has selected for a new strain of western corn rootworm that oviposit in crops 
Table 1. Default western corn rootworm life table parameters used in the models

\begin{tabular}{lcccc}
\hline \multicolumn{1}{c}{ Stage } & Duration $(\mathrm{d})$ & Mortality/d & Eggs/female/d & 0 \\
Neonate & 2 & $0.29^{a}$ & 0 & 0 \\
Larva & $21^{b}$ & $0.0914^{c}$ & 0 & 0 \\
Pupa & $10^{b}$ & $0.028^{d}$ & 0 & 0 \\
Preovipositional adult & $13^{e}$ & 0.0 & $0.0113^{f}(15 \%$ for stage $)$ & $0.002(5.6 \%$ for stage $)$ \\
Young adult & $28^{e, g, h}$ & $0.01^{h, i}$ & $7.5^{h}$ & $0.002(1.8 \%$ for stage $)$ \\
Old adult & 9 & $0.0245^{h, i}$ & & 0 \\
\hline
\end{tabular}

${ }^{a}$ Strnad and Bergman (1987); Branson (1989).

${ }^{b}$ Jackson and Elliott (1988)

${ }^{c}$ Elliott et al. (1989); Elliott and Hein (1991).

${ }^{d}$ Fisher (1986).

${ }^{e}$ Branson and Johnson (1973); Hill (1975).

${ }^{f}$ Coats et al. (1986); Naranjo (1990).

g Quiring and Timmins (1990); Branson et al. (1977); Ball (1957).

${ }^{h}$ Elliott et al. (1990)

${ }^{i}$ Elliott et al. (1991).

other than corn, thus allowing populations to circumvent crop rotation as a management tactic (Sammons et al. 1997, O’Neal et al. 1999, Isard et al. 2000).

The occurrence of insecticide resistance in Nebraska represents another example of how western corn rootworms have adapted to a management tactic. Between 1952 and 1954, the cyclodienes, such as aldrin, chlordane, and heptachlor, were introduced as soil insecticides for larval control (Metcalf 1986). The insecticides were rapidly adopted by growers in $\mathrm{Ne}-$ braska, with nearly 700,000 ha treated with these three compounds in 1954 (Ball and Weekman 1962). Ineffective larval control with the cyclodienes was first observed in south central Nebraska in 1959, and 100fold resistance was documented by 1961, <10 yr after introduction (Ball and Weekman 1962).

Organophosphate and carbamate insecticides were introduced soon after the failure of the cyclodienes. Growers in south central Nebraska began using these compounds in aerial control programs to suppress beetle populations and to prevent egg laying, thereby managing larval injury the following season (Meinke 1995). The primary insecticide used in the initial beetle control programs was carbaryl, formulated as Sevin 4-Oil by Union Carbide (Mayo 1976) followed in later years with Sevin XLR. In 1980, Penncap-M (microencapsulated methyl-parathion; Elf Atochem North America, Inc., Philadelphia, PA) was approved for use in field corn (Stoner et al. 1982). Growers in this region slowly adopted Penncap-M, and by the early 1990s, it had replaced carbaryl as the primary insecticide for beetle control because of its extended residual activity. However, reports of beetle control failures with Penncap-M began to increase in south central Nebraska during the early 1990s (Wright et al. 1996), and resistance to methyl-parathion was documented in the region by 1995 (Meinke et al. 1998).

The distribution of organophosphate resistance among Nebraska western corn rootworm populations has changed significantly since its first documentation in 1995 (Meinke et al. 1998). Areas initially shown to be susceptible have since become resistant, and as resistance expands there are areas of vastly different susceptibilities separated by relatively small geo- graphical distances. The objectives of this study were to develop and validate a stochastic simulation model that predicts the evolution of organophosphate resistance in western corn rootworm populations of Nebraska. The validated model could then be used to help assess resistance risk for management strategies designed to sustain novel rootworm control tactics that may be implemented in the future.

\section{Materials and Methods}

A stochastic, individual-based, multifield model based on published corn rootworm life table data was used to simulate the evolution of resistance to methylparathion in western corn rootworms. The model simulated random draws from binomial probability distributions for dispersal, survivorship, mating, and fecundity (in that order) daily. Because of the stochastic nature of the model, all simulations were replicated five times.

Life Table Traits. We assumed that corn rootworms were physiologically active for $\approx 140 \mathrm{~d} / \mathrm{yr}$ from egg hatch to first killing frost. We simulated those $140 \mathrm{~d}$ daily. The life table parameters used in the model are summarized in Table 1 . Yearly overwintering survivorship was randomly drawn from a normal distribution with a mean of 0.5 and a variance of 0.25 with limits of 0.05 and 1.0 .

Eclosion from eggs occurred over a mean of $29 \mathrm{~d}$ for males and $32 \mathrm{~d}$ for females (Musick and Fairchild 1971, Branson 1976, Palmer et al. 1977, Krysan et al. 1984, Levine et al. 1992). Adult emergence was simulated with a normal distribution with a mean of $45 \mathrm{~d}$ and a standard deviation of $9.5 \mathrm{~d}$ for the females and $7 \mathrm{~d}$ for the males (Nowatzki 2001). Female emergence was delayed for $3 \mathrm{~d}$ relative to male emergence.

Pesticide Response. An objective of the model was to simulate the evolution of resistance to the methylparathion (Penncap-M) aerial adulticidal corn rootworm control program, so we used data on the response of western corn rootworm to this insecticide. We assumed that resistance was expressed as a dominant monogenic trait (Parimi et al. 2003); therefore, heterozygous and homozygous resistant individuals 
were equally likely to survive exposure to methylparathion. A single application of methyl-parathion would kill $98.5 \%$ of susceptible individuals in the field (see consultants survey below), whereas $50 \%$ of resistant individuals with homozygous or heterozygous genotypes also were killed. We assumed no fitness costs were associated with resistance alleles nor did dispersal behavior of resistant individuals differ from that of susceptible individuals. Efficacy from a single spray decayed with a half-life of $10 \mathrm{~d}$, and a total period of residual activity equivalent to $20 \mathrm{~d}$ (Mayo and Newtton 1984). Resistance was determined by the failure of the spray program to reduce beetle populations in the field below a maximum acceptable density of 0.5 gravid females per plant (measured after daily mortality and dispersal between fields had occurred). Sprays were automatically applied, so this density is not a spray threshold, but a threshold to determine when growers were no longer obtaining satisfactory control with methyl-parathion applications. The average plant population per field was assumed at 30,000 plants per acre. A matrix of 25 fields, all treated uniformly, was used for these simulations.

Consultant Survey. To document the evolution of methyl-parathion resistance as it was observed in the field, individual interviews with 10 Nebraska crop consultants were conducted during November 2001-January 2002. The consultants selected were members of the Nebraska Independent Crop Consultants Association and worked in Phelps County, Nebraska, or one of its bordering counties during the period methylparathion was used in Nebraska for adult corn rootworm management and when resistance first became apparent. Interviews followed a standard written questionnaire that was provided to crop consultants before the interview. The questions were designed to obtain information about when methyl-parathion use for adult rootworm management began in south central Nebraska and how its efficacy changed over time, and to obtain realistic estimates for the major operational parameters involved in the development of resistance.

Model Corroboration. The population dynamics properties of the model were qualitatively corroborated by comparing the simulated population dynamics with one of several sets of empirical population dynamics data published by Short and Hill (1972). Because published population dynamics data on larval development were limited, we focused on comparing female emergence, preovipositional female numbers, and gravid female numbers between empirical data reported for field populations in Nebraska and the simulated fields. The population genetics component of the model was verified by comparing the predicted time to resistance with the time-period reported by grower consultants for resistance to develop in the field.

Initial Resistance Allele Frequency. Because we were modeling a retrospective case of resistance evolution, it was possible to estimate parameters associated with the genetics of resistance $\left(\mathrm{LC}_{50}\right.$, slope of the dose-mortality curve, and dominance of resistance).
Table 2. Parameters varied in the initial resistance allele frequency and sensitivity analyses

\begin{tabular}{l}
\hline Parameter \\
\hline Mortality rate \\
Neonate \\
Larva \\
Pupa \\
Young adult \\
Old adult \\
Dispersal rate \\
Preovipositional adult \\
Young adult \\
Old adult \\
Fecundity \\
Young adult \\
Old adult \\
Overwintering emergence variance \\
Male \\
Female \\
Density dependence \\
Maximum pop \\
Genetics of resistance \\
SS LC \\
RS LC
\end{tabular}

At the start of each simulation, each parameter was randomly drawn from a normal distribution with a mean of the default value of the parameter and a standard deviation equal to $10 \%$ of the mean. All rates were limited to biologically feasible values. For example, mortality and dispersal rates were limited to between 0 and 1 . The $\mathrm{LC}_{50}$ of the

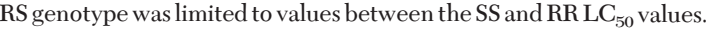

We could not, however, estimate the initial resistance allele frequency from the available data. We chose, a priori, five values $\left(10^{-2}, 10^{-3}, 10^{-4}, 10^{-5}\right.$, and $\left.10^{-6}\right)$ as candidate initial allele frequencies to cover a likely range of estimates. For each candidate value, we ran 1000 simulations, randomly varying each of 18 biological parameters for each simulation (Table 2). Each parameter was varied by making a random draw from a normal distribution with the mean equal to our default parameter and a standard deviation equal to $10 \%$ of the parameter value. Thus, $\approx 95 \%$ of the values used in the simulations were in the range of $80-120 \%$ of the default value. We limited the resulting distributions to those simulations that did not result in extinction and where control failures took longer than 3 yr to evolve (these were examples where the random parameters chosen resulted in the pesticide never working and really are cases of tolerance rather than resistance). We then calculated from the resulting distributions the likelihood that a candidate initial allele frequency existed given that resistance evolved in a specified time frame by using Bayesian inference (Carpenter 1990, Haefner 1996). In the absence of previous information, we assumed that the prior probabilities for the three candidate frequencies were all 0.2 . Weighting these likelihoods with the reported appearance of resistance by Meinke et al. (1997) allowed us to estimate which candidate initial resistance allele frequency was most likely to result in the model simulating a time frame similar to that observed in the field. 
Sensitivity Analysis. To determine the model's sensitivity to variations in the biological parameters, we varied the same 18 parameters in the same manner as in the initial frequency experiment (Table 2), running 2,000 simulations with an initial resistance allele frequency of $1 \times 10^{-5}$. In this example, however, we saved the parameter values, the time it took for control failures to occur in the simulated fields as well as the rate of increase in the resistance allele frequency after $3 \mathrm{yr}$. The time to control failure incorporates both the time it took for resistance to evolve, as well as some time for the population to rebuild to threshold levels. The latter measure is a relative estimate of the rate at which resistance evolved in that simulation. The rate of change of the frequency of a rare resistance allele is approximately constant and related to the relative fitness of the heterozygotes compared with susceptible homozygotes. The rate of change measurement is therefore a relative measure of the rate at which resistance evolved in a simulation without regard to a population rebounding in the field. The degree to which these two estimates are correlated is an estimate of the importance of resistance genetics and population dynamics in field control failures for the western corn rootworm.

To determine model sensitivity to variation in parameters, we conducted a multiple, stepwise regression for each of the two resistance measurements. To stabilize variances for the rate measurement, we first $\log$ transformed the rate variable. We performed both forward and backward stepwise regression, in all cases with $P<0.005$, to determine whether a coefficient should either be included or removed from the regression. We examined residuals from each regression for outliers and verified that they approximated a normal distribution. A limitation of this sensitivity analysis is that all parameters were drawn independently, assuming that there was no covariance between parameters. Although a limitation of the field data available, it is possible that there could be ecological trade-offs between these parameters leading to covariance structures.

Spray Timing. To determine how sensitive the time until control failures occurred was to variations in the timing of the single adulticide spray of methyl-parathion, we simulated three spray dates, each $10 \mathrm{~d}$ apart. The early spray date (day 52) was synchronized with the first appearance of gravid females, the median spray date (day 62 ) occurred when $\approx 10 \%$ of the females were gravid, and the later spray date (day 72) occurred when $\approx 50 \%$ of the females were gravid.

Multiple Spray Applications. During the latter years of beetle management with methyl-parathion in $\mathrm{Ne}$ braska, many fields required more than one application during the growing season to maintain beetle populations below threshold levels (Meinke et al. 1997). To determine whether the use of multiple sprays significantly impacted the longevity of the beetle control program, we simulated a second spray applied $14 \mathrm{~d}$ after the first. The use of a second spray was incorporated into the simulation model beginning in
Table 3. Time line of methyl-parathion (Penncap-M) performance as observed by crop consultants in the Phelps County, Nebraska, region

\begin{tabular}{ccccc}
\hline \hline Consultant & $\begin{array}{c}\text { First yr } \\
\text { of use }\end{array}$ & $\begin{array}{c}\text { Yr until } \\
\text { reduced } \\
\text { control }\end{array}$ & $\begin{array}{c}\text { Yr until } \\
\text { control } \\
\text { failure }\end{array}$ & $\begin{array}{c}\text { Yr until } \\
\text { abandoned }\end{array}$ \\
\hline 1 & 1990 & 4 & 5 & 8 \\
2 & 1985 & 5 & 10 & 10 \\
3 & $-^{a}$ & - & - & - \\
4 & 1983 & 5 & 9 & 15 \\
5 & 1990 & 4 & 5 & 8 \\
6 & 1991 & 3 & 8 & 9 \\
7 & 1989 & 8 & - & - \\
8 & - & - & 8 & 10 \\
9 & 1986 & 7 & 7 & - \\
10 & 1989 & 7 & $5.6 \pm 1.85$ & $9.9 \pm 2.41$ \\
\hline
\end{tabular}

${ }^{a}$ Response not included because consultant either started consulting in the region after Penncap-M was already in use by their growers, or they left the area before it was abandoned.

the sixth year. We then compared the mean time to control failure with and without this second spray.

\section{Results and Discussion}

Consultant Survey. The consultants that were interviewed influenced rootworm management decisions on a total of 86,600 ha of cropland annually in Phelps County or one of its bordering counties, and they had been consulting in the region for an average of $18 \pm 5.9 \mathrm{yr}$. During the initial period of methylparathion use, all consultants reported that one spray application provided very high levels of beetle control, initially reducing populations by an average of $97 \pm$ $2.7 \%$ with $7-14 \mathrm{~d}$ of residual activity. All consultants stated this level of control sufficiently maintained beetle populations below threshold levels for the remainder of the growing season.

All 10 consultants interviewed reported a reduction in beetle control with methyl-parathion (not explained by weather conditions or product application problems) after methyl-parathion use began in their area (Table 3). A reduction in beetle control was first observed an average of $5.4 \pm 1.8 \mathrm{yr}$ after methylparathion was initially used (Table 3 ). The consultants defined reduced control as a reduction in residual activity and responded by recommending a two-spray program by using increased application rates to maintain beetle populations below threshold levels.

Efficacy continued to decline over time, and all 10 consultants reported experiencing beetle control failures at some time with methyl-parathion, averaging $7.6 \pm 1.85 \mathrm{yr}$ after it was initially used (Table 1 ). A control failure was defined as greatly reduced initial knockdown of the population, and the inability of two or three applications to reduce beetle populations below threshold levels. In response to control failures, consultants initially recommended a variety of control options, including the application of other active ingredients (dimethoate, bifenthrin, or cyhalothrin) either alone or tank-mixed with methyl-parathion, or the use of a soil insecticide for larval control during the 

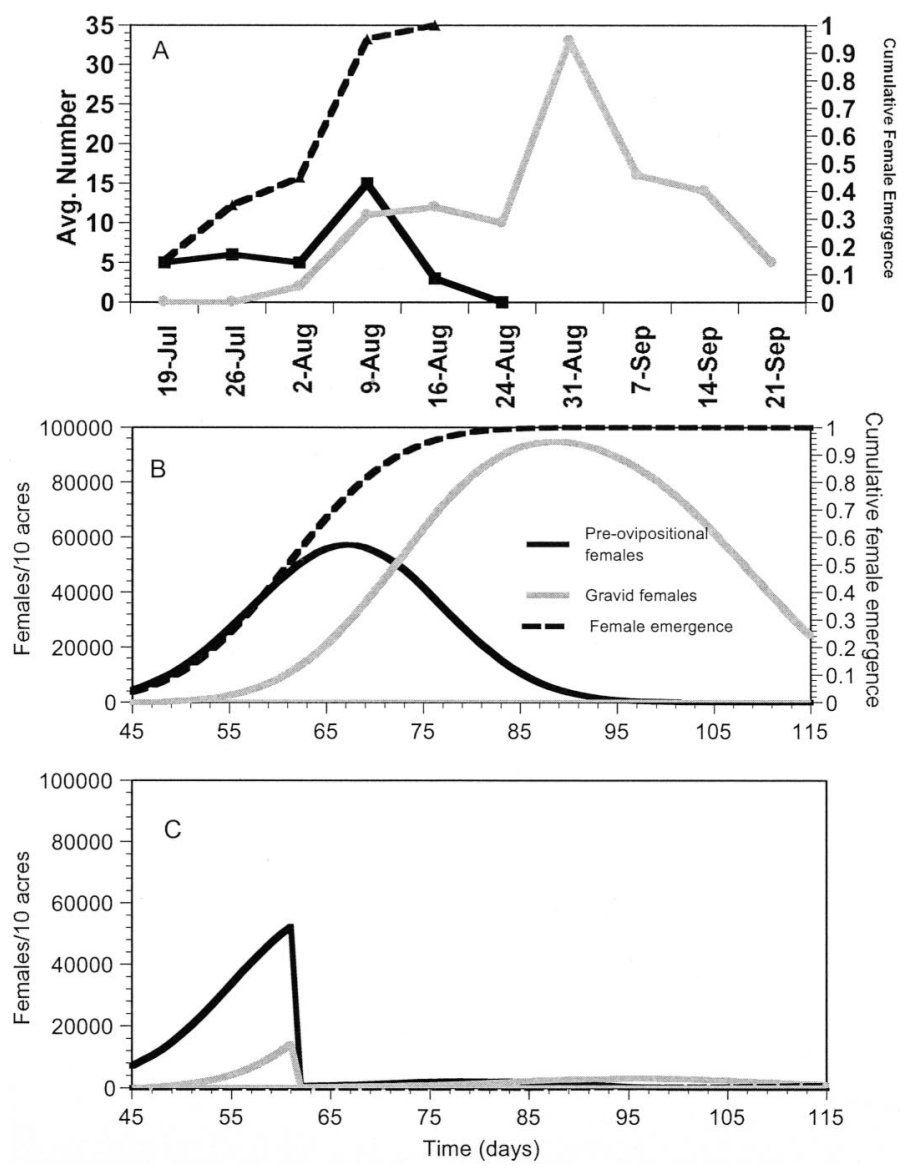

Fig. 1. Comparison of field population dynamics with simulated population dynamics. (A) Summary of field data reported by Short and Hill (1972) for North Platte, NE. (B) Simulated population dynamics for an untreated field. (C) Simulated population dynamics for a field treated once per year.

following season. Because of poor efficacy and increasing control costs, methyl-parathion was abandoned as a beetle management tool by the consultants an average of $9.9 \pm 2.41 \mathrm{yr}$ after it was initially used (Table 3).

Model Corroboration. The population dynamics of the model closely resembled those measured in the field (Short and Hill 1972) (Fig. 1). As with all models, the simulated results are an approximation and not an exact duplicate of observations collected in the field. Although it is difficult to determine whether the fit between observed and simulated results are satisfactory, we trust the model contains sufficient detail to adequately describe the population dynamics of corn rootworms and to meet the objectives proposed for the model. The default parameters we incorporated into the model suggested that resistance could have evolved within $8.5 \mathrm{yr}$ (Table 4; Fig. 2), well within the time frame reported by crop consultants in the region where resistance occurred.

Initial Resistance Allele Frequency. Resistance evolved an average of $4.3 \mathrm{yr}$ earlier when the initial resistance allele frequency was $10^{-4}$ than when the frequency was $10^{-6}$ (Fig. $2 ; F=37.1 ; \mathrm{df}=2,27 ; P<$
0.001). All parameters in these simulations, with the exception of initial resistance allele frequency, remained constant, so the variability observed was only because of stochastic factors.

The modes of the distribution of the time to control failure in the field from 1000 simulations were not different from the mean values determined from using only the default parameter values (Fig. 3). Each decrease of an order of magnitude in the initial resistance allele frequency increased the time until resistance evolved by $\approx 2 \mathrm{yr}$. This relationship is consistent with a linear rate of increase in the time to resistance with the log of resistant allele frequency. With an initial resistance allele frequency of $10^{-4}$, these simulations suggest one would have to lower the initial resistance allele frequency by 4 orders of magnitude to double the time it took for resistance to evolve.

The results of the Bayesian inference analysis (Table 4) suggest that a model using an initial resistance allele frequency of $1 \times 10^{-4}$ would be most likely to result in the observed results (of the five models tested). The probability of this model explaining the observed results, given the observed simulation distributions and the error analysis (random variation of 
Table 4. Bayesian inference of the likelihood of the five candidate initial resistance allele frequencies $\left[\Sigma\left(\mathbf{P}\left(\operatorname{IRF}_{\mathbf{j}} \mid \mathbf{Y e a r}\right)^{*} \mathbf{G D}\right)\right]$ given the observed distribution of the time until beetle control failures occurred in the field as reported by commercial crop consultants (GD) and the distributions of simulated model results by using randomly varied parameter inputs $\left[\mathrm{P}\left(\mathrm{Year} \mid \mathrm{IRF}_{\mathrm{j}}\right)\right]$

\begin{tabular}{|c|c|c|c|c|c|c|c|c|c|c|c|}
\hline & \multicolumn{5}{|c|}{$\mathrm{P}\left(\right.$ Year $\left.\mid \operatorname{IRF}_{\mathbf{j}}\right)$} & \multicolumn{5}{|c|}{$\mathrm{P}\left(\mathrm{IRF}_{\mathrm{j}} \mid\right.$ Year $)$} & \multirow{2}{*}{$\begin{array}{l}\text { Consultant } \\
\text { distribution } \\
\text { (GD) }\end{array}$} \\
\hline & $10^{--2}$ & $10^{--3}$ & $10^{--4}$ & $10^{--5}$ & $10^{--6}$ & $10^{--2}$ & $10^{--3}$ & $10^{--4}$ & $10^{--5}$ & $10^{--6}$ & \\
\hline 4 & 0.325 & 0.015 & 0.010 & 0.010 & 0.009 & 0.879 & 0.042 & 0.027 & 0.0281 & 0.024 & 0 \\
\hline 5 & 0.357 & 0.129 & 0.010 & 0.006 & 0.003 & 0.708 & 0.256 & 0.020 & 0.011 & 0.005 & 0.25 \\
\hline 6 & 0.182 & 0.265 & 0.046 & 0.005 & 0.001 & 0.366 & 0.531 & 0.092 & 0.009 & 0.003 & 0 \\
\hline 7 & 0.076 & 0.242 & 0.124 & 0.024 & 0.005 & 0.161 & 0.513 & 0.263 & 0.051 & 0.011 & 0.125 \\
\hline 8 & 0.034 & 0.168 & 0.221 & 0.068 & 0.005 & 0.068 & 0.338 & 0.446 & 0.137 & 0.010 & 0.25 \\
\hline 9 & 0.014 & 0.102 & 0.179 & 0.119 & 0.040 & 0.30 & 0.225 & 0.395 & 0.262 & 0.088 & 0.25 \\
\hline 10 & 0.007 & 0.040 & 0.139 & 0.155 & 0.065 & 0.017 & 0.099 & 0.342 & 0.381 & 0.161 & 0.125 \\
\hline 11 & 0.003 & 0.025 & 0.084 & 0.147 & 0.123 & 0.010 & 0.065 & 0.220 & 0.384 & 0.322 & 0 \\
\hline 12 & 0.001 & 0.007 & 0.057 & 0.124 & 0.152 & 0.003 & 0.021 & 0.167 & 0.362 & 0.446 & 0 \\
\hline 13 & 0.0 & 0.005 & 0.037 & 0.088 & 0.133 & 0.0 & 0.020 & 0.140 & 0.334 & 0.506 & 0 \\
\hline 14 & 0.0 & 0.001 & 0.037 & 0.080 & 0.117 & 0.0 & 0.004 & 0.158 & 0.340 & 0.498 & 0 \\
\hline 15 & 0.0 & 0.0 & 0.011 & 0.059 & 0.088 & 0.0 & 0.0 & 0.070 & 0.372 & 0.558 & 0 \\
\hline 16 & 0.0 & 0.0 & 0.010 & 0.035 & 0.077 & 0.0 & 0.0 & 0.083 & 0.285 & 0.632 & 0 \\
\hline 17 & 0.0 & 0.0 & 0.010 & 0.024 & 0.045 & 0.0 & 0.0 & 0.127 & 0.306 & 0.566 & 0 \\
\hline 18 & 0.0 & 0.0 & 0.004 & 0.021 & 0.033 & 0.0 & 0.0 & 0.076 & 0.355 & 0.569 & 0 \\
\hline 19 & 0.0 & 0.0 & 0.004 & 0.010 & 0.035 & 0.0 & 0.0 & 0.090 & 0.210 & 0.699 & 0 \\
\hline \multirow[t]{2}{*}{20} & 0.0 & 0.0 & 0.004 & 0.014 & 0.019 & 0.0 & 0.0 & 0.119 & 0.369 & 0.512 & 0 \\
\hline & \multicolumn{5}{|c|}{$\Sigma\left(\mathrm{P}\left(\mathrm{IRF}_{\mathrm{j}} \mid\right.\right.$ Year $\left.) * \mathrm{GD}\right)$} & 0.224 & 0.281 & 0.291 & 0.157 & 0.047 & \\
\hline
\end{tabular}

We assume no knowledge about the prior distributions of the initial gene frequencies $\left[\mathrm{P}\left(\mathrm{IRF}_{\mathrm{j}}\right)\right]$ and set all five equal to 0.20 . The table has been truncated at $20 \mathrm{yr}$, although all calculations were conducted on the full (29-yr) table.

parameters), was $29 \%$, followed closely by $10^{-3}$ (28\%) and $10^{-2}(22 \%)$. The probability of the model incorporating an initial resistance allele frequency of $1 \times 10^{-5}$ was $16 \%$, whereas the probability of the last model $\left(1 \times 10^{-6}\right)$ was $<5 \%$, suggesting that this initial resistance allele frequency was unlikely.

Sensitivity Analysis. We performed multiple linear regression for all 18 parameters that were varied on the two measures of resistance: the time to control failure in the field and the rate of increase in the resistance allele frequency after $3 \mathrm{yr}$ of simulating a single spray per year (Tables 5 and 6). Similar genetic parameters were incorporated into both models with the exception that the response of the homozygous susceptible genotype $\left(\mathrm{SS} \mathrm{LC}_{50}\right.$ ), which was considered to be a marginal variable in the field failure regression. Both regressions also incorporated the variance in male and female emergence curves. These parameters are probably important because they determine the number of

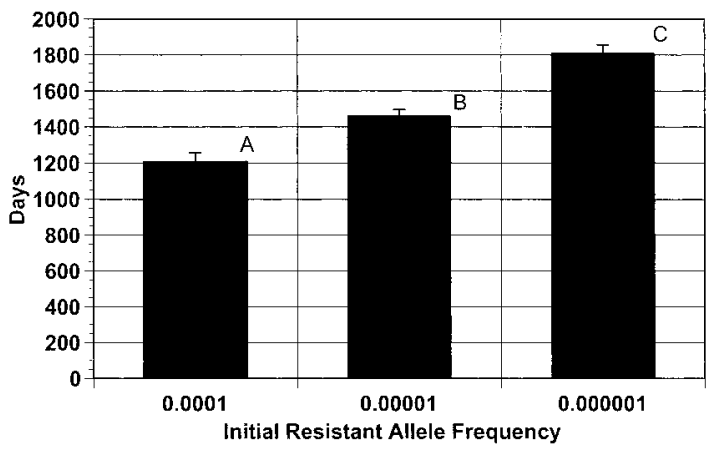

Fig. 2. Mean \pm SD time until field failure $(>15,000$ gravid females per acre) of simulations run with default parameters but with different initial resistance allele frequencies, $140 \mathrm{~d}$ occur per year. insects that are exposed to a single application. As the variance in the emergence pattern changed, the proportion of the population that had still not emerged when the toxin was applied to fields also changed. Dispersal parameters were not significant in either regression, probably because we simulated a small, uniform set of fields that were all treated identically. The simulated environment was typical, however, of the region in Nebraska where resistance to methylparathion did evolve. Future simulations will address multiple habitat environments. The two regressions differed considerably in their incorporation of parameters that affect the rate of increase in the population (mortality and fecundity rates). These parameters were highly significant in the field failure regression, and the terms with the highest standardized coefficients were among this class of parameters. In contrast, these terms were not significant in the rate of increase regression, suggesting that growth rate parameters did not have a large direct impact on the evolution of resistance. These results suggest that the loss of methyl-parathion efficacy in Nebraska was the result of a two-step process. Initially, population growth rates were negative and the population size decreased. During this period, selection rapidly increased the resistant allele frequency. Once the resistance allele reached a high enough frequency, the population growth rate again became positive and the population began to rebound. The speed at which the population rebounded to damaging levels during this second phase was directly related to the population growth rate. The importance of this second phase in the occurrence of beetle control failures in the field is indicated by the low Pearson's correlation coefficient $(-0.194)$ between the natural log of the rate of resistance and the observed time to field failures. 

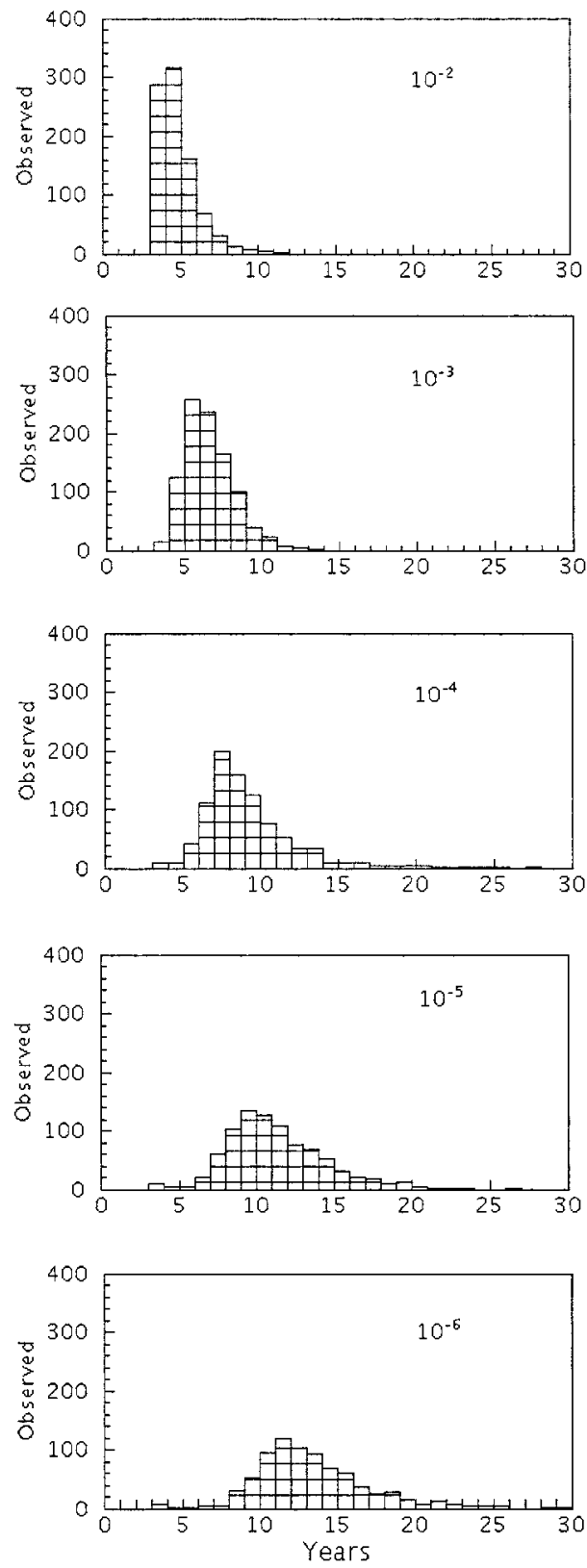

Fig. 3. Distributions of the time to field failure for 1000 simulations with parameters randomly drawn from normal distributions with a mean of the default parameter value and a standard deviation of $10 \%$ of the mean. The initial resistance allele frequencies were held constant at 0.01, 0.001, 0.0001, 0.00001 , and 0.000001 for each set of simulations.

Spray Timing. The mean time to control failure was different for each of the three application dates (Fig. $4 ; F=105.1 ; \mathrm{df}=2,12 ; P<0.001$ ). When the application was made early in the emergence curve, control failures occurred $\approx 20 \%$ faster than the median spray date. The sprays were in this case marginally effective (Fig. 5A), and although the resistant allele was not as common, the population exceeded our predetermined control failure guidelines $(15,000 \mathrm{fe}-$ males per acre) early. These simulations demonstrate the difference between genetic resistance and a performance-based measure of resistance. When sprays were applied late (Fig. 5C), the spray program did not control the ovipositing female beetles and control failures occurred in the second year of the program.

These simulations suggest that there was a relatively small window of perhaps $10 \mathrm{~d}$ over which the single methyl-parathion spray could be applied and still maintain adequate control of the populations. The median spray date not only resulted in the highest level of population suppression and most rapid evolution of resistance but also provided the longest time until control failures with the adulticide program.

Multiple Spray Dates. The second spray had no discernible impact on the rate of resistance evolution $(t=-0.84, \mathrm{df}=8, P=0.43)$. The population dynamics of the two-spray regime closely resemble those of the single spray regime (Fig. 6). We suggest the second spray had little impact on the rate of resistance evolution because the population was essentially genetically resistant after just $5 \mathrm{yr}$, and most of the subsequent 5 yr were an interaction of limited impact from the spray and the time required for the population to rebound from the low sizes resulting from the early years of the adulticide program. Because heritable variation for a dominant trait actually decreases as the allele becomes common, relatively little change in the resistance allele frequency occurred over the second $5 \mathrm{yr}$ (in direct contrast to a recessive trait). The implication of these results is that any resistance management program for methyl-parathion should have been implemented within the first 5 yr of the adulticide program. Attempts to implement resistance management in the final $5 \mathrm{yr}$ would have had low probability of success.

Conclusions. We have developed a model retrospectively describing the evolution of resistance to adulticidal sprays of methyl-parathion among populations of western corn rootworm. The population dynamics observed in the model resembles that reported for field populations. There also was close concordance between the estimated time until field failures because of the inability of methyl-parathion to maintain populations below critical densities and the times observed by commercial crop consultants in the region where resistance developed. As with any biological system, there was considerable uncertainty with regard to various biological parameters, either because a reliable estimate for the parameter was not reported in the literature or because of the inherent difficulty associated with estimating certain parameters to which accurate field data are lacking. We attempted to incorporate this uncertainty by randomly varying parameters and by running the model many times. Our goal was not to obtain single estimates from the model, but rather to develop probability distributions of likely outputs given parameter uncertainty. Because of the stochastic nature of the model, and because of the inevitability of parameter uncertainty, 
Table 5. Results from a stepwise linear regression of 18 randomly varied parameters on the simulated time until beetle control failures were observed in fields

\begin{tabular}{lcccc}
\hline \hline \multicolumn{1}{c}{ Parameter } & Coefficient & $\begin{array}{c}\text { Standardized } \\
\text { coefficient }\end{array}$ & $F$ & $P$ \\
\hline Terms included in regression & & & & \\
Neonate mortality & 4630.2 & 0.233 & 261.6 & $<0.0001$ \\
Larval mortality & 40166.0 & 0.631 & 1911 & $<0.0001$ \\
Pupal mortality & 17184 & 0.087 & 36.3 & $<0.0001$ \\
Young adult mortality & 18926 & 0.084 & $<0.0001$ \\
Young adult fecundity & -49.02 & -0.252 & $<0.0001$ \\
Male emergence & 77.4 & 0.104 & 307.1 & $<0.0001$ \\
Female emergence & -107.11 & -0.170 & 139.4 & $<0.0001$ \\
RS LC & -222.87 & -0.200 & 192.3 & 0.0016 \\
Slope of dose-mortality curve & 80.79 & 0.046 & 15.7 & 0.0001 \\
Residual activity of spray & 30.61 & 0.057 & & 0.142 \\
Terms removed from regression & & & 0.115 & 0.706 \\
Old adult mortality & & & 0.373 & 0.734 \\
Preovipositional adult dispersal & & & 0.140 & 0.541 \\
Young adult dispersal & & & 0.432 & 0.708 \\
Old adult dispersal & & & 0.75 & 0.511 \\
Old adult fecundity & & & 0.005 \\
SS LC & & & 0.356 \\
RR LC & & & 0.575 \\
Max pop size & & & \\
\hline
\end{tabular}

The standardized coefficient is the amount of change, in standard deviation units, in the dependent variable when an independent variable changes by one standard deviation unit.

we feel that these distributions are a better description of model output than are single value outputs.

The results presented here suggest that the initial resistance allele frequency was most likely $>1 \times 10^{-6}$ when the adulticide program by using methyl-parathion was initiated. Although it is certainly possible to design parameter sets that would support any of the five candidate initial resistance allele frequencies, we limited this problem by randomly varying all parameters in the model. The parameter distribution estimates [the $\mathrm{P}\left(\right.$ Year $\left.\mathrm{IRF}_{\mathrm{j}}\right)$ columns in Table 4] therefore incorporate parameter uncertainty in those distributions. We would not suggest that simulations are an ideal method to estimate initial allele frequencies. However, given that the opportunity to actually measure the frequencies has been lost, simulations represent the best tools to gather and organize current data and rank hypotheses about initial gene frequencies. Bayesian inference is an ideal tool in this case because it allows us to estimate the likelihood of different hypotheses given the observed data, whereas frequentist statistics are focused on the likelihood of the observed events given that a specific hypothesis is true. It is, however, important to understand that the

Table 6. Results from a stepwise linear regression of 18 randomly varied parameters on the simulated rate of resistance evolution measured as the natural logarithm of the ratio of the resistance allele frequency after 3 yr relative to the initial resistance allele frequency

\begin{tabular}{|c|c|c|c|c|}
\hline Parameter & Coefficient & $\begin{array}{c}\text { Standardized } \\
\text { coefficient }\end{array}$ & $F$ & $P$ \\
\hline \multicolumn{5}{|l|}{ Terms included in regression } \\
\hline Male emergence & -0.372 & -0.276 & 639.2 & $<0.00001$ \\
\hline Female emergence & -0.446 & -0.392 & 1291 & $<0.00001$ \\
\hline $\mathrm{SS} \mathrm{LC}_{50}$ & -5.433 & -0.405 & 1376 & $<0.00001$ \\
\hline $\mathrm{RS} \mathrm{LC}_{50}$ & 0.696 & 0.345 & 998.3 & $<0.00001$ \\
\hline Slope of the dose-mortality curve & 1.554 & 0.485 & 1968 & $<0.00001$ \\
\hline Residual activity of spray & 0.137 & 0.142 & 169.6 & $<0.00001$ \\
\hline \multicolumn{5}{|l|}{ Terms removed from regression } \\
\hline Neonate mortality & & & 3.193 & 0.074 \\
\hline Larval mortality & & & 4.593 & 0.032 \\
\hline Pupal mortality & & & 0.046 & 0.831 \\
\hline Young adult mortality & & & 1.218 & 0.270 \\
\hline Old adult mortality & & & 0.830 & 0.362 \\
\hline Preovipositional adult dispersal & & & 0.053 & 0.818 \\
\hline Young adult dispersal & & & 0.098 & 0.754 \\
\hline Old adult dispersal & & & 0.633 & 0.426 \\
\hline Young adult fecundity & & & 2.800 & 0.094 \\
\hline Old adult fecundity & & & 0.844 & 0.358 \\
\hline $\mathrm{RR} \mathrm{LC}_{50}$ & & & 4.751 & 0.029 \\
\hline Max pop size & & & 1.251 & 0.264 \\
\hline
\end{tabular}

The standardized coefficient is the amount of change, in standard deviation units, in the dependent variable when an independent variable changes by one standard deviation unit. 


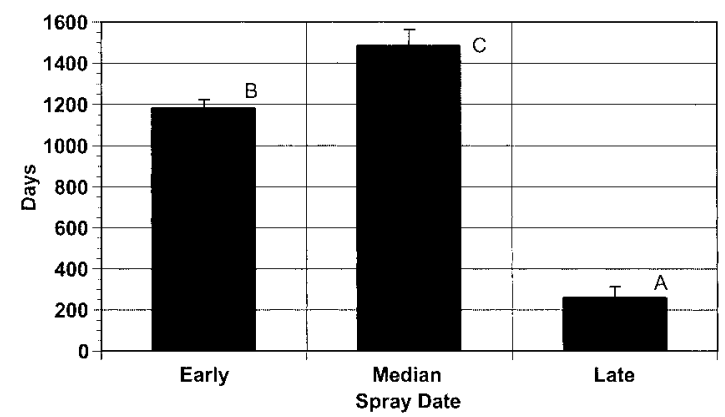

Fig. 4. Effect of spray timing on the time to field control failure of methyl-parathion; $140 \mathrm{~d}$ occur per year. The early spray date was when gravid females first occurred, the median spray date was when $\approx 10 \%$ of the females were gravid, and the late spray was applied when $\approx 50 \%$ of the females were gravid.
Bayesian approach only evaluates the candidate hypotheses. The Bayesian approach does not identify the overall optimal model, only the candidate model that most likely would result in the observed results. In contrast, a conventional null hypothesis only determines the likelihood of observing the data given that the single model being evaluated is true and hence also does not determine the optimal model.

Variation and Model Stability. Our methodology for sensitivity analysis in this article differed significantly from previous approaches. A common approach to sensitivity analysis is to identify variables that are thought to be important and to vary those parameters over a range while maintaining all other parameters at constant or default values. This method suffers from several limitations. First, only the parameters identified by the researchers as important are varied. Sec-
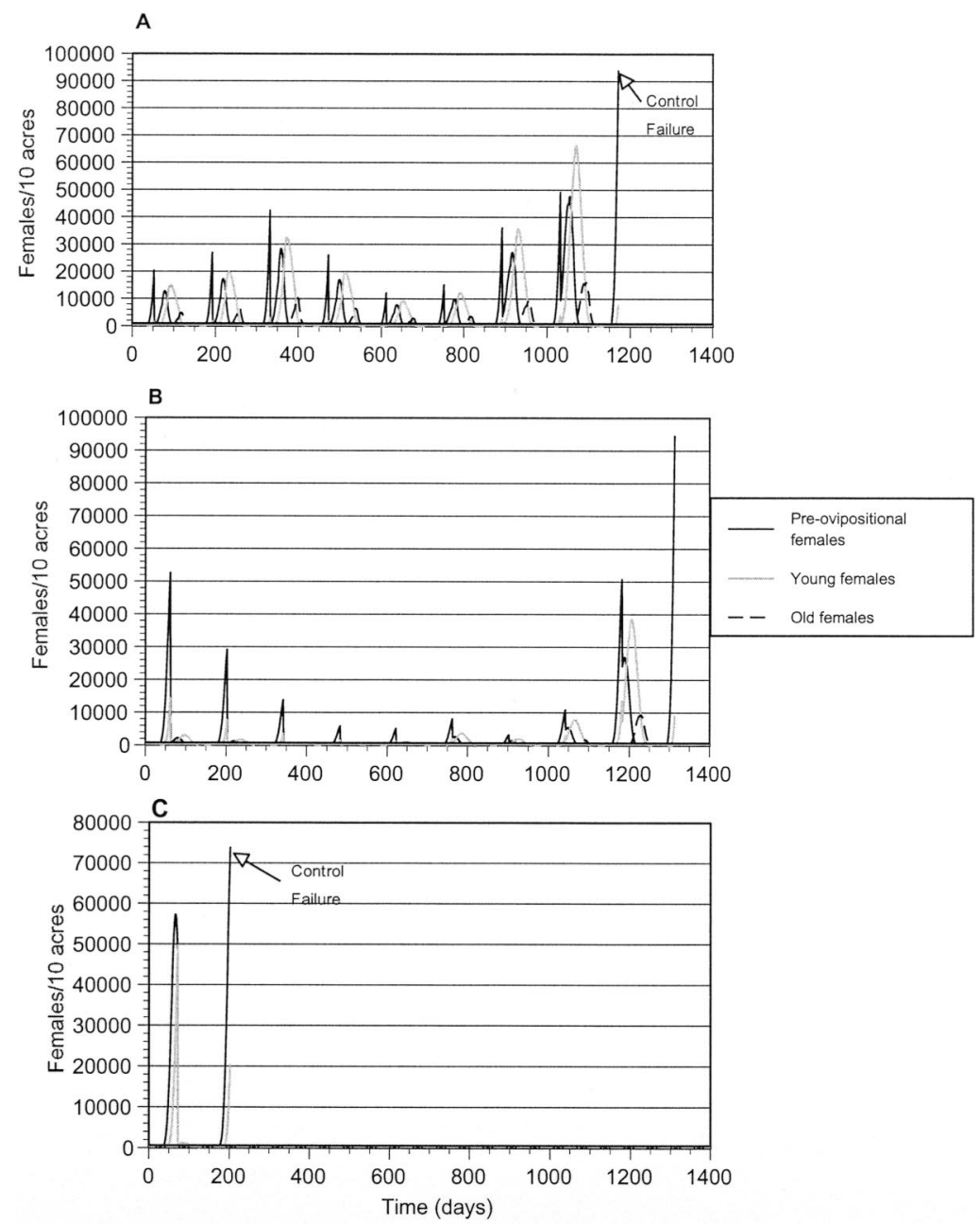

Fig. 5. Effect of spray timing on population dynamics and the development of control failures to methyl-parathion. The early spray date was when gravid females first occurred, the median spray date was when $\approx 10 \%$ of the females were gravid, and the late spray was applied when $\approx 50 \%$ of the females were gravid. 


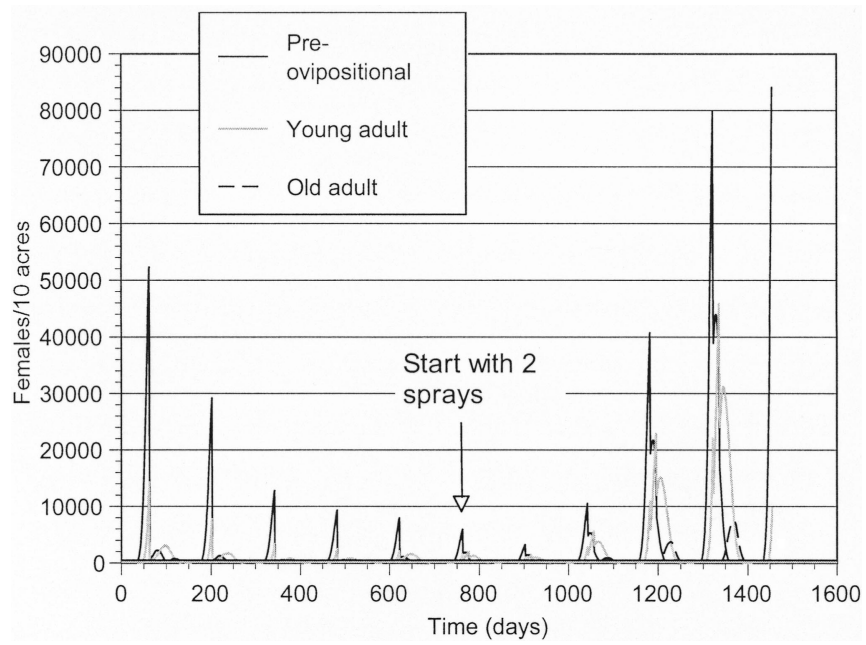

Fig. 6. Population sizes for three age groups from a single simulation in which a one methyl parathion spray was simulated for the first $5 \mathrm{yr}$, and two sprays $10 \mathrm{~d}$ apart were simulated for the remaining years.

ond, the sensitivity of parameters is only examined with the other parameters set to default values, and interactions between parameters are not considered. If a parameter is important only when a second parameter is at a nondefault value, the sensitivity of the model to the first parameter may not be identified. For example, Caprio and Tabashnik (1992) found that the effects of gene flow were dependent on the values used for the initial resistance allele frequency. Our method of sensitivity analysis differed because we randomly varied all the parameters in the model and used linear regression to identify the most important parameters. This removes the bias of the researcher choosing which parameters to vary for sensitivity analysis. We did not initially expect the model to demonstrate much sensitivity with respect to growth rate parameters and would probably not have included those parameters in a traditional sensitivity analysis. It is more difficult to establish the importance of testing the potential for interactions between variables. An alternative approach of varying parameters over specific values and using analysis of variance (ANOVA) would be more appropriate for identifying these relationships, although the number of potential interaction terms would be daunting. We suggest first identifying sensitive parameters that have important impacts on model predictions using linear regression and then using ANOVA to determine whether interactions are important among this smaller subset of parameters. Although this approach may still not identify all interactions, it would improve current techniques that do not attempt to identify any interactions.

\section{References Cited}

Ball, H. J. 1957. On the biology and egg-laying habits of the western corn rootworm. J. Econ. Entomol. 50: 126-128.

Ball, H. J., and G. T. Weekman. 1962. Insecticide resistance in the adult western corn rootworm in Nebraska. J. Econ. Entomol. 55: 439-441.
Branson, T.F. 1976. Variability and hatching pattern of eggs of the western corn rootworm exposed to chill periods of different durations. Entomol. Exp. Appl. 19: 77-81.

Branson, T. F. 1989. Survival of starved neonate larvae of Diabrotica virgifera virgifera LeConte (Coleoptera: Chrysomelidae). J. Kans. Entomol. Soc. 62: 521-523.

Branson, T. F., and R. D. Johnson. 1973. Adult western corn rootworms: oviposition, fecundity, and longevity in the laboratory. J. Econ. Entomol. 66: 417-418.

Branson, T. F., P. L. Guss, and J. J. Jackson. 1977. Mating frequency of the western corn rootworm. Ann. Entomol. Soc. Am. 70: 506-508.

Caprio, M. A., and B. E. Tabashnik. 1992. Gene flow accelerates local adaptation among finite populations: simulating the evolution of insecticide resistance. J. Econ. Entomol. 85: 611-620.

Carpenter, S. R. 1990. Large-scale perturbations: opportunities for innovation. Ecology 71: 2038-2043.

Coats, S. A., J. J. Tollefson, and J. A. Mutchmor. 1986. Study of migratory flight in the western corn rootworm (Coleoptera: Chrysomelidae). Environ. Entomol. 15: 1-6.

Elliott, N. C., G. R. Sutter, T. F. Branson, and J. R. Fisher. 1989. Effect of population density of immatures on survival and development of the western corn rootworm (Coleoptera: Chrysomelidae). J. Entomol. Sci. 24: 209213.

Elliott, N. C., R. D. Gustin, and S. L. Hanson. 1990. Influence of adult diet on the reproductive biology and survival of the western corn rootworm, Diabrotica virgifera virgifera. Entomol. Exp. Appl. 56: 15-21.

Elliott, N. C., and G. L. Hein. 1991. Population dynamics of the western corn rootworm: formulation, validation, and analysis of a simulation model. Ecol. Model. 59: 93-122.

Elliott, N. C., J. J. Jackson, G. R. Sutter, and D. A. Beck. 1991. A descriptive study of the population dynamics of adult Diabrotica virgifera virgifera (Coleoptera: Chrysomelidae) in artificially infested corn fields. Great Lakes Entomol. 24: 159-167.

Fisher, J. R. 1986. Development and survival of pupae of Diabrotica virgifera virgifera and $D$. undecimpunctata howardi (Coleoptera: Chrysomelidae) at constant temperatures and humidities. Environ. Entomol. 15: 626-630. 
Haefner, J. W. 1996. Modeling biological systems: principles and applications. Chapman \& Hall, New York.

Hill, R. E. 1975. Mating, oviposition patterns, fecundity and longevity of the western corn rootworm. J. Econ. Entomol. 68: 311-315.

Isard, S. A., J. L. Spencer, M. A. Nasser, and E. Levine. 2000. Aerial movement of western corn rootworm (Coleoptera: Chrysomelidae): diel periodicity of flight activity in soybean fields. Environ. Entomol. 29: 226-234.

Jackson, J. J., and N. C. Elliott. 1988. Temperature-dependent development of immature stages of the western corn rootworm, Diabrotica virgifera virgifera (Coleoptera: Chrysomelidae). Environ. Entomol. 17: 166-171.

Krysan, J. L., J. J. Jackson, and A. C. Lew. 1984. Field termination of egg diapause in Diabrotica with new evidence of extended diapause in D. barberi (Coleoptera: Chrysomelidae). Environ. Entomol. 13: 1237-1240.

Levine, E., and H. Oloumi-Sadeghi. 1991. Management of diabroticite rootworms in corn. Annu. Rev. Entomol. 36: $229-255$.

Levine, E., and H. Oloumi-Sadeghi. 1996. Western corn rootworm (Coleoptera: Chrysomelidae) larval injury to corn grown for seed production following soybeans grown for seed production. J. Econ. Entomol. 89: 1010 1016.

Levine, E., H. Oloumi-Sadeghi, and C. R. Ellis. 1992. Thermal requirements, hatching patterns, and prolonged diapause in western corn rootworm (Coleoptera: Chrysomelidae) eggs. J. Econ. Entomol. 85: 2425-2432.

Mayo, Z. B. 1976. Aerial suppression of rootworm adults for larval control. Department of Entomology Report No. 2. The Agricultural Experiment Station, University of Nebraska-Lincoln.

Mayo, Z. B., and J. P. Newtton. 1984. Influence of rainfall and sprinkler irrigation on the residual activity of insecticides applied to corn for control of adult western corn rootworm, Diabrotica virgifera virgifera (Coleoptera: Chrysomelidae). J. Econ. Entomol. 77: 190-193.

Meinke, L. J. 1995. Adult corn rootworm management. University of Nebraska Agricultural Research Division Miscellaneous Publication 63.

Meinke, L. J., B. Siegfried, R. Wright, and L. Chandler. 1997. Western corn rootworm resistance to insecticides: current situation in Nebraska, pp. 88-92. In Proceedings, Illinois Agricultural Pest Conference, January 1997, Urbana, IL.

Meinke, L. J., B. D. Siegfried, R. J. Wright, and L. D. Chandler. 1998. Adult susceptibility of Nebraska western corn rootworm (Coleoptera: Chrysomelidae) populations to selected insecticides. J. Econ. Entomol. 594-600.
Metcalf, R. L. 1986. Foreword, pp. vii-xv. In J. L. Krysan and T. A. Miller [eds.], Methods for the study of pest Diabrotica. Springer, New York.

Musick, G. J., and M. L. Fairchild. 1971. Field studies on rate of hatch of western corn rootworm eggs in Missouri during 1965-68. J. Econ. Entomol. 64: 9-11.

Naranjo, S. E. 1990. Comparative flight behavior of Diabrotica virgifera virgifera and Diabrotica barberi in the laboratory. Entomol. Exp. Appl. 55: 79-90.

Nowatzki, T. M. 2001. Improvements in management of corn rootworms (Coleoptera: Chrysomelidae). Ph.D. dissertation, Iowa State University, Ames, IA.

O’Neal, M. E., M. E. Gray, and C. A. Smyth. 1999. Population characteristics of a western corn rootworm (Coleoptera: Chrysomelidae) strain in East-central Illinois corn and soybean fields. J. Econ. Entomol. 92: 1301-1310.

Palmer, D. F., L. K. French, and H. C. Chiang. 1977. Effects of chill temperatures on developing western corn rootworm eggs. Environ. Entomol. 6: 862-864.

Parimi, S., M. E. Scharf, L. J. Meinke, L. D. Chandler, and B. D. Siegfried. 2003. Inheritance of methyl-parathion resistance in Nebraska western corn rootworm populations (Coleoptera: Chrysomelidae). J. Econ. Entomol. 96: 131-136.

Quiring, D. T., and P. R. Timmins. 1990. Influence of reproductive ecology on feasibility of mass trapping Diabrotica virgifera virgifera (Coleoptera: Chrysomelidae). J. Appl. Ecol. 27: 965-982.

Sammons, A. E., C. R. Edwards, L. W. Bledsoe, P. J. Boeve, and J. J. Stuart. 1997. Behavioral and feeding assays reveal a western corn rootworm (Coleoptera: Chrysomelidae) variant that is attracted to soybean. Environ. Entomol. 26: 1336-1342.

Short, D. E., and R. E. Hill. 1972. Adult emergence, ovarian development, and oviposition sequence of the western corn rootworm in Nebraska. J. Econ. Entomol. 65: 685689.

Stoner, A., B. Rose, and W. T. Wilson. 1982. Microencapsulated insecticides: their current status in relation to beekeeping in the USA. Bee World 63: 72-76.

Strnad, S. P., and M. K. Bergman. 1987. Movement of firstinstar western corn rootworms (Coleoptera: Chrysomelidae) in soil. Environ. Entomol. 16: 975-978.

Wright, R. J., L. J. Meinke, and B. D. Siegfried. 1996. Corn rootworm management and insecticide resistance, pp. 45-53. In Proceedings 1996 Crop Protection Clinic, Cooperative Extension, University of Nebraska, Lincoln.

Received 9 June 2003; accepted 30 September 2005. 